\title{
The economic impact from the decreasing population mobility of China's mainland during the epidemic
}

\author{
Yi Xiao ${ }^{1}$, Jian Peng ${ }^{2}$, Yuan Chen ${ }^{1}$ and Zheming Yuan ${ }^{1, *}$ \\ 1 Hunan Engineering \& Technology Research Centre for Agricultural Big Data Analysis \& Decision-making, \\ Hunan Agricultural University, Changsha, Hunan, 410128, China \\ 2 College of Information and Intelligence, Hunan Agricultural University, Changsha, Hunan, 410128, China \\ * Correspondence: zhmyuan@sina.com;
}

\begin{abstract}
The COVID-19 pandemic caused by SARS-CoV-2 poses a devastating threat to human society in terms of health, economy and lifestyle. Establishing accurate and real-time models to predict and assess the impact of the epidemic on the economy is instructive. We have designed a new model to quantitatively assess the impact of the COVID-19 on the economy of China's mainland. The nominal GDP in the Q1 of 2020 that we predicted for China's mainland with the Baidu Migration Data is RMB 20,785.7 billion, which is less by $3.59 \%$ than that in 2019. The estimated value is confirmed roughly by the official report released in April 17, 2020 (RMB 20,650 billion, 6.8\% yearon-year declined). Strict control measures during the epidemic have greatly reduced China's economic activity and had a serious impact on the country's economy. Orderly promotion of population mobility plays a decisive role in economic recovery.
\end{abstract}

Keywords: Economic impact; Population mobility data; Prediction; Assess; Covid-19

JEL Classification:

$\mathrm{C} 15 ; \mathrm{C} 31 ; \mathrm{C} 51 ; \mathrm{C} 53 ; \mathrm{C} 55 ; \mathrm{C} 63 ; \mathrm{I} 18$

\section{Introduction}

The COVID-19 hit Wuhan, China on December 29, 2019 and spread quickly across entire mainland [1]. As for April 12, 2020, 82052 were infected by the virus, and the deaths were 3339. The 31 provinces in China's mainland raised their public health response level to the highest level (level-1) on January 29, 2020. To contain the spread of the epidemic, Chinese government has to adopt a series of large-scale public health interventions, such as inter- and intra-city travel restrictions, Staying Home Exercise, and Keeping Social Distancing. These immediate and decisive measures have brought the epidemic under effective control in early March [2,3], but have also significantly restricted the population mobility in China's mainland [4]. According to the Baidu Migration Data, the inter-city travelers and the intra-city activity intensity in 346 cities in the Q1 of 2020 were 1.266 billion and 123218 , which are less by $36.25 \%$ and $12.90 \%$ when compared to that in the same period of last year (1.985 billion and 141479) respectively (Fig.1).

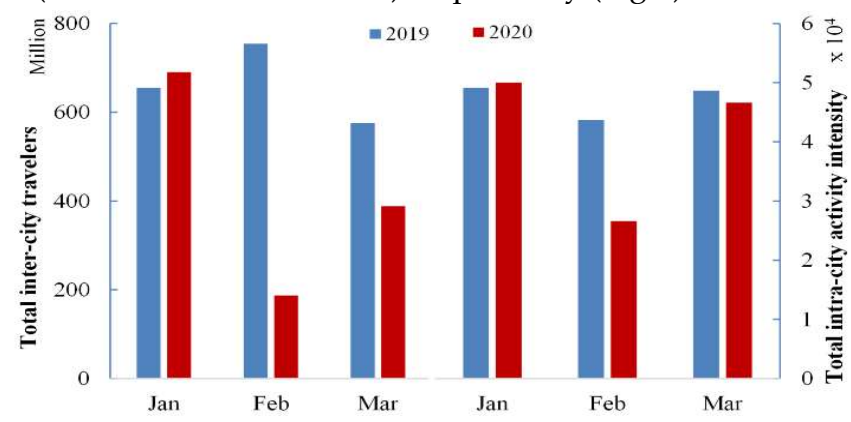

Figure1. The population mobility in the Q1 of 2019 and 2020 in China's mainland

Data source: Baidu Migration website 
The population mobility, especially the inter-city and the inter-province travels, involving transportation, accommodation, catering, business activities, sightseeing and shopping, has close associations with the regional economy [57]. The nationwide travel restriction has brought the entire service industry including transportation, catering, tourism, entertainment, and offline business, into a stagnation. The manufacturing supply chains have been hit heavily or even been partially broken. All of these have enormous negative impacts on the social and economic activities in the Q1 of 2020 in China's mainland. According to a recent report from the National Bureau of Statistics, some economic indicators in China dropped sharply in January and February of the year 2020 when compared to that in the same period of last year, such as the fixed asset investment(-24.5\%), the total retail sales of consumer goods(-20.5\%), the exports(-15.9\%), the industrial added value $(-13.5 \%)$, the service industry production index $(-13 \%)$ and the profits of large-scale industrial enterprises(-38.3\%).

The Purchasing Manager Index (PMI) is an international macroeconomic monitoring index [8]. The mean PMI was 45.9 in the Q1 of 2020 in China's Mainland, which is less by $7.65 \%$ and $8.02 \%$ than that in the Q1 and the Q4 of 2019 respectively. PMI is a leading indicator predicting GDP and usually has 3-6 months ahead [9], however, it is obviously invalid to predict the GDP for the Q1 of 2020 through the PMI of the Q3 or Q4 of 2019 when the epidemic heavily hit the economy. Economists, banks and institutions, etc. predicted at the early stage of the epidemic that the GDP growth rate of China in the Q1 of 2020 would decrease from 6\% to 1.2\% 4.4\%, for example 1.2\% (China Economic Situation Report Website), 1.4\%(Bloomberg), 2.5\% (Goldman Sachs Asia), 2.8\%(Standard Chartered) and 4.4\%(Chinese Academy of Social Sciences). However, the predicted value dropped sharply to negative growth, $-4.2 \% \sim-11 \%$, when the epidemic has spread further to the world and seriously affected China's exports, for example, $-4.2 \%$ (Standard Chartered), $5 \%$ (Morgan Stanley), $-6 \% \sim-10 \%(J u s t i n$ Lin), $-6.48 \%$ (20 chief economists of China Business News), $-9 \%($ Goldman Sachs Asia) and $-11 \%$ (Bloomberg). Evaluating the real impact of the epidemic on China's GDP in the Q1 of 2020 needs to develop a new quantitative predicting model. Based on the population mobility data from the Baidu Migration and the GDP data of 31 provinces in China's mainland in the Q1 of 2019, we established a multiple regression model and predicted the GDP of each province in the Q1 of 2020, and the real impact of the epidemic on the economy of China's mainland was also assessed.

\section{Materials and Methods}

\subsection{Data sources}

The GDP data and the population size in 2019 and 2020 of each province are from National Bureau of Statistics of China (http://www.stats.gov.cn/) and its affiliates. The population mobility data on inter-city and inter-province from January 1, 2020 to March 31, 2020 (including the same period data in 2019) in China's mainland is from the Baidu Migration (Baidu Inc., Beijing, China. http://qianxi.baidu.com), which is a largescale dataset based on an application that tracks the movements of mobile phone users and publishes the data in real time [10]. The Baidu platform represents the inter-city travel population of each city with the immigration and emigration indicators. The intensity of intra-city population movements in each city is the ratio of the number of people travelling within a city to the number of residents in the city [4].

\subsection{Model design}

In the economic field, many methods, such as the Auto-regressive Integrated Moving Average Model and the Purchasing Managers' Index, are used for predicting and evaluating the GDP. These methods often rely on the parameters of a stationary time series and the results are lagging [11-13]. When certain major events causing large fluctuations in economic indicators occur, these forecasting methods will become unreliable. In response to the impact of the epidemic on the global economy, we estimated a model based on real-time population migration data to predict and evaluate the impact of the epidemic on the economy in time.

\subsection{Select parameters for the model}

At the level of province, we checked the relationship between the GDP in the Q1 of 2019 among the total emigration index of travelers leaving for other provinces, the total inter-city emigration index within the province, the population size; the determined coefficient were $0.7362,0.7000$ and 0.6981 , respectively. The relationship between the population mobility index and the GDP is significantly stronger than that between the PMI and the GDP, respectively as: 0.44 [14], 0.514 [15] and 0.75 [16], which shows that the population mobility index can be used to predict GDP in real-time. As for the population development index, there is a strong correlation between the previous economic inverse ranking of a 
certain region and the subsequent economic development in the same period [17], so we further checked the inverse ranking of the provincial GDP, and the determined coefficient was 0.7743 .

The emigration index of travelers leaving from the $i^{\text {th }}$ province to other provinces on the $j^{\text {th }}$ day is denoted as $\mathrm{PEI}_{i j}$ $\left(i=1,2, \ldots, 31 ; j=1,2, \ldots, 90\right.$ for 2019 and $1,2, \ldots, 91$ for 2020). The emigration index of travelers leaving from the $k^{\text {th }}$ city of the $i^{\text {th }}$ province to other districts on the $j^{\text {th }}$ day is denoted as $\mathrm{CEI}_{k i j}\left(k=1,2, \ldots, m ; m\right.$ is the total number of cities in the $i^{\text {th }}$ province). Ratiokij represents the percentage of the number of travelers leaving from the $k^{\text {th }}$ city of the $i^{\text {th }}$ province to other cities in the same province to the total number of travelers leaving from the $k^{\text {th }}$ city on the $j^{\text {th }}$ day. $\mathrm{PEI}_{i j}, \mathrm{CEI}_{k i}$ and Ratiokij are all listed in the Baidu Migration.

For each province, the total emigration index of travelers leaving from the $i^{\text {th }}$ province to other provinces from January and February in 2019 can be calculated by the equation (1):

$x_{1 i}=\sum_{j=1}^{59} \mathrm{PEI}_{i j},(i=1,2, \ldots 31)$

$x_{2 i}=\sum_{j=1}^{59} \sum_{k=1}^{m} \mathrm{CEI}_{k i j} \cdot$ Ratio $_{k i j}(i=1,2, \ldots 27)$

For each city, its $x_{2 r}(r=28=$ "Beijing", 29="Chongqing", 30="Shanghai", 31="Tianjin") can be represented with the mean $x_{2 i}$ of 27 provinces and adjusted by the population:

$x_{2 r}=\frac{\sum_{i=1}^{27} x_{2 i}}{\sum_{i=1}^{27} x_{5 i} / 27} \times x_{5 r},(r=28=" B e i j i n g ", 29=$ "Chongqing", $30=$ "Shanghai", $31=$ "Tianjin")

For each province, the total emigration index of travelers leaving from the $i^{\text {th }}$ province to other provinces in March 2019 can be calculated by the equation (4):

$x_{3 i}=\sum_{j=60}^{90} \operatorname{PEI}_{i j},(i=1,2, \ldots 31)$

The total inter-city emigration index within the same province in March 2019 can be calculated by the equation (5):

$x_{4 i}=\sum_{j=60}^{90} \sum_{k=1}^{m} \mathrm{CEI}_{k i j} \cdot$ Ratio $_{k i j},(i=1,2, \ldots 27)$

Similarly, $x_{4 r}$ of each city can be calculated by the equation (6):

$x_{4 r}=\frac{\sum_{i=1}^{27} x_{4 i}}{\sum_{i=1}^{27} x_{5 i} / 27} \times x_{5 r},(r=28,29,30,31)$

$x_{5}$ : the population size of each province in 2019, represented with the population of 2018 end.

$X_{6}$ : the inverse ranking of the provincial GDP in the Q1 of 2019, represented with the ranking of the same period in 2018. Y: the nominal GDP (RMB) of each province in the Q1 of 2019.

The data of the Q1 of 2019 for each province are listed in Table 1. 
Table 1. The nominal GDP and the population mobility data of each province in the Q1 of 2019.

\begin{tabular}{|c|c|c|c|c|c|c|c|}
\hline Province & $x_{1}$ & $x_{2}$ & $x_{3}$ & $x_{4}$ & $x_{5} \times 10^{4}$ & $x_{6}$ & $Y \times 10^{9}$ \\
\hline Anhui & 530.5 & 718.1 & 196.8 & 258.6 & 6323.6 & 21 & 7065.7 \\
\hline Fujian & 251.4 & 429.8 & 78.1 & 153.6 & 3941.0 & 24 & 8145.3 \\
\hline Gansu & 127.4 & 238.2 & 54.0 & 106.9 & 2637.3 & 5 & 1736.5 \\
\hline Guangdong & 1061.6 & 2125.6 & 266.8 & 867.5 & 11346.0 & 31 & 23886.8 \\
\hline Guangxi & 314.7 & 588.3 & 100.8 & 194.0 & 4926.0 & 13 & 4225.3 \\
\hline Guizhou & 267.4 & 428.6 & 96.4 & 157.9 & 3600.0 & 10 & 3205.8 \\
\hline Hainan & 79.0 & 305.5 & 32.5 & 136.5 & 934.3 & 4 & 1300.3 \\
\hline Hebei & 644.6 & 430.6 & 323.5 & 225.6 & 7556.3 & 19 & 8164.4 \\
\hline Henan & 564.9 & 1033.9 & 220.7 & 476.6 & 9605.0 & 27 & 11639.1 \\
\hline Heilongjiang & 130.8 & 280.9 & 50.7 & 114.4 & 3773.1 & 6 & 3184.6 \\
\hline Hubei & 369.6 & 723.4 & 125.1 & 280.3 & 5917.0 & 25 & 9110.1 \\
\hline Hunan & 418.6 & 824.2 & 127.7 & 277.1 & 6898.8 & 23 & 8335.0 \\
\hline Inner Mongolia & 185.2 & 237.3 & 81.6 & 102.6 & 2534.0 & 11 & 3578.5 \\
\hline Jilin & 125.9 & 274.1 & 50.9 & 128.0 & 2704.1 & 7 & 2701.8 \\
\hline Jiangsu & 803.0 & 979.2 & 341.6 & 388.2 & 8050.7 & 30 & 22883.8 \\
\hline Jiangxi & 328.4 & 368.3 & 102.7 & 114.6 & 4647.6 & 16 & 5373.1 \\
\hline Liaoning & 193.1 & 442.0 & 82.3 & 205.0 & 4359.3 & 17 & 5486.2 \\
\hline Ningxia & 53.9 & 123.9 & 24.0 & 56.8 & 688.1 & 3 & 752.4 \\
\hline Qinghai & 34.6 & 61.4 & 15.3 & 32.6 & 603.2 & 2 & 557.1 \\
\hline Shaanxi & 257.0 & 564.3 & 103.6 & 239.3 & 3864.4 & 12 & 5450.3 \\
\hline Shandong & 430.2 & 914.8 & 199.8 & 427.2 & 10047.2 & 29 & 20177.4 \\
\hline Shanxi & 203.3 & 398.8 & 94.5 & 186.4 & 3718.3 & 18 & 3533.2 \\
\hline Sichuan & 485.3 & 1209.0 & 165.5 & 427.4 & 8341.0 & 26 & 9653.2 \\
\hline Tibet & 12.0 & 15.9 & 4.4 & 8.2 & 343.8 & 1 & 324.1 \\
\hline Xinjiang & 49.5 & 231.9 & 15.9 & 120.1 & 2486.8 & 8 & 2177.7 \\
\hline Yunnan & 194.1 & 573.5 & 71.2 & 221.0 & 4829.5 & 14 & 3849.7 \\
\hline Zhejiang & 703.4 & 551.3 & 221.9 & 214.9 & 5737.0 & 28 & 13084.1 \\
\hline Beijing & 594.8 & 1117.8 & 273.6 & 554.5 & 2154.2 & 20 & 7409.6 \\
\hline Chongqing & 329.2 & 1708.5 & 107.4 & 663.9 & 3101.8 & 15 & 5102.3 \\
\hline Shanghai & 510.8 & 1117.8 & 232.6 & 665.7 & 2423.8 & 22 & 8308.3 \\
\hline Tianjin & 219.7 & 869.3 & 104.4 & 418.7 & 1559.6 & 9 & 5198.6 \\
\hline
\end{tabular}

Data source: Baidu Migration website and National Bureau of Statistics of China website Notes:

Notes:

$x_{1}$ : The total emigration index of travelers leaving for other provinces from January to February in 2019.

$x_{2}$ : The total inter-city emigration index within the same province from January to February in 2019.

$x_{3}$ : The total emigration index of travelers leaving for other provinces in March, 2019.

$x_{4}$ : The total inter-city emigration index within the same province in March,2019.

$x_{5}$ : The population size of each province in 2019.

$x_{6}$ : The inverse ranking of the provincial GDP in the Q1 of 2018

Y: The nominal GDP of each province in the Q1 of 2018. 


\subsection{The construction of the regression equation}

The epidemic in China's mainlandhas been brought under effective control in early March of 2020. On March 18, zero newly confirmed case was first reported. At the beginning of March, all provinces except Hubei began to recover economic activities orderly, and the population mobility in March was significantly higher than that in February. The share of the GDP in March to the GDP in the Q1 is usually 40\%. Taking January, February and March as a whole, the importance of March will be diluted and the predicted value will be decreased. To avoid the disturbance of the "Spring Festival" when comparing the economic indexes among different years or months, the GDP of January and February has always been viewed as a whole by the National Bureau of statistics. According to Table 1, the GDP of January and February $\left(Y_{1-2}\right)$ and the GDP of March $\left(Y_{3}\right)$ of each province can be predicted by the follow regression models.

$Y_{1-2}=0.6 \times Y=6.3621 \times x_{1}+0.02842 \times x_{2}+0.3015 \times x_{5}+58.8302 \times x_{6}\left(n=31, R^{2}=0.8304, P<10^{-7}\right)$

$Y_{3}=0.4 \times Y=5.7604 \times x_{3}+1.1471 \times x_{4}+0.2686 \times x_{5}+47.9784 \times x_{6}\left(n=31, R^{2}=0.8265, P<10^{-7}\right)$

The true and fitted values of the provincial GDP in the Q1 of 2019 are shown in figure 2.
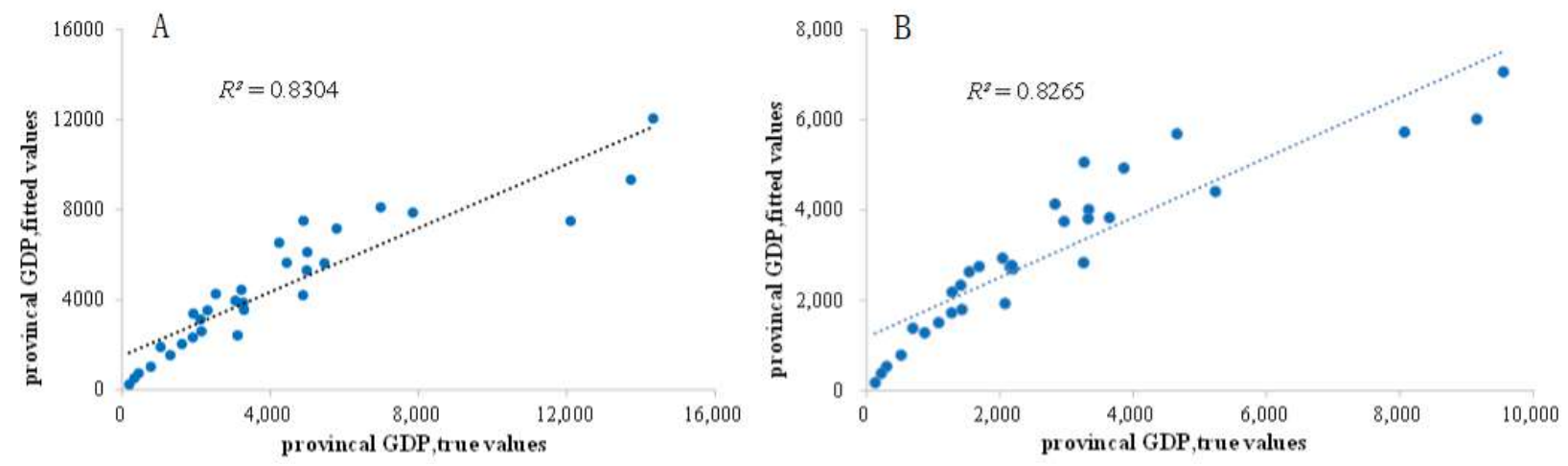

Figure 2. The true and fitted GDP values of 31 provinces in China's mainland in the Q1 of 2019

Data source: National Bureau of Statistics of china website

Notes:Figure 2A represents the GDP of January and February $\left(Y_{1-2}\right)$,Figure $2 \mathrm{~B}$ represents the GDP of March ( $\left.Y_{3}\right)$

\subsection{The predicted GDP for the Q1 of 2020}

The GDP of March has a heavy share in the GDP of the Q1(40\%), and the population movements in March, 2020 experienced an obvious increasing when compared with that in February. And at the same time, the National Bureau of Statistics has always consolidated the January's and February's GDP each year for avoiding the Year-on-Year and Month-on-Month disturbance of the factor of the Spring Festival on the economic indicators of January and February. So, we will construct respectively the multiple regression models with no constants for the January-February GDP( $Y_{1-}$ 2) and the March's $\operatorname{GDP}\left(Y_{3}\right)$ of each province in 2019 [18].

$Y^{\prime}{ }_{1-2}=0.6 \times Y=c_{1} \times x^{\prime}{ }_{1}+c_{2} \times x^{\prime}{ }_{2}+c_{3} \times x^{\prime}{ }_{5}+c_{4} \times x^{\prime}{ }_{6}$

$Y^{\prime}{ }_{3}=0.4 \times Y=c_{1} \times x^{\prime}{ }_{3}+c_{2} \times x^{\prime}{ }_{4}+c_{3} \times x^{\prime}{ }_{5}+c_{4} \times x^{\prime}{ }_{6}$

$x^{\prime}{ }_{1}, x^{\prime}{ }_{2}, x^{\prime}{ }_{3}, x^{\prime}{ }_{4}, x^{\prime}{ }_{5}$ and $x^{\prime}{ }_{6}$ of 2020 are corresponding to $x_{1}, x_{2}, x_{3}, x_{4}, x_{5}$ and $x_{6}$ of 2019 , respectively.

$x^{\prime}{ }_{1}$ : The total emigration index of travelers leaving for other provinces from January to February in 2020

$x^{\prime}{ }_{2}$ : The total inter-city emigration index within the same province from January to February in 2020

$x^{\prime}{ }_{3}$ : The total emigration index of travelers leaving for other provinces in March, 2020

$x^{\prime}{ }_{4}$ : The total inter-city emigration index within the same province in March, 2020

$x^{\prime}{ }_{5}$ : The population size of each province in 2020, represented with the population at the end of 2019.

$x^{\prime}{ }_{6}$ : The inverse ranking of the provincial GDP in the Q1 of 2019 
$Y^{\prime}:$ The predicted nominal GDP of each province in the Q1 of 2020

Feeding the regression models with the corresponding population mobility data in the Q1 of 2020, we got the predicted GDPs of January and February $\left(Y^{\prime}{ }_{1-2}\right)$ and the predicted GDPs of March $\left(Y^{\prime}{ }_{3}\right)$ for each province in 2020 . In the Q1 of 2020, the consumer price index (CPI) rose by 4.9\% year-on-year (National Bureau of Statistics 2020), the predicted GDPs in the Q1 of 2020 for each province $\left(Y^{\prime}\right)$ can be adjusted by the following formula, and are listed in Table 2.

$Y^{\prime}=\left(Y^{\prime}{ }_{1-2}+Y^{\prime}{ }^{\prime}\right) \times 1.049 \quad\left(n=31, R^{2}=0.8907, P<10^{-7}\right)$

Table 2. The population mobility data and the predicted nominal GDP in the Q1 of 2020 for each province

\begin{tabular}{|c|c|c|c|c|c|c|c|}
\hline Province & $x_{1}^{\prime}$ & $x_{2}^{\prime}$ & $x_{3}^{\prime}$ & $x_{4}^{\prime}$ & $x_{5}^{\prime} \times 10^{4}$ & $x_{6}^{\prime}$ & $Y^{\prime} \times 10^{9}$ \\
\hline Anhui & 312.8 & 383.4 & 187.5 & 172.7 & 6365.9 & 21 & 9599.3 \\
\hline Fujian & 178.4 & 272.2 & 46.6 & 131.5 & 3973.0 & 24 & 6703.2 \\
\hline Gansu & 71.3 & 142.5 & 40.0 & 79.8 & 2647.4 & 5 & 2961.1 \\
\hline Guangdong & 848.0 & 1454.2 & 127.4 & 856.8 & 11521.0 & 31 & 17866.3 \\
\hline Guangxi & 194.0 & 366.5 & 96.5 & 148.4 & 4960.0 & 13 & 6489.6 \\
\hline Guizhou & 160.8 & 296.5 & 109.5 & 150.4 & 3620.0 & 10 & 5209.7 \\
\hline Hainan & 54.3 & 175.2 & 13.5 & 86.1 & 944.7 & 4 & 1565.7 \\
\hline Hebei & 379.3 & 255.8 & 160.9 & 116.9 & 7592.0 & 19 & 10320.7 \\
\hline Henan & 304.4 & 568.8 & 206.1 & 274.7 & 9640.0 & 27 & 12413.8 \\
\hline Heilongjiang & 77.5 & 151.4 & 28.5 & 46.1 & 3759.0 & 6 & 3669.4 \\
\hline Hubei & 148.8 & 300.9 & 86.3 & 63.8 & 5932.0 & 25 & 7948.1 \\
\hline Hunan & 273.6 & 505.3 & 123.6 & 205.2 & 6918.4 & 23 & 9548.8 \\
\hline Inner Mongolia & 108.8 & 141.2 & 45.9 & 70.7 & 2539.6 & 11 & 3844.1 \\
\hline Jilin & 80.1 & 143.4 & 28.4 & 61.0 & 2692.0 & 7 & 3177.9 \\
\hline Jiangsu & 546.3 & 595.4 & 196.0 & 311.1 & 8070.0 & 30 & 13408.8 \\
\hline Jiangxi & 197.6 & 221.6 & 105.2 & 81.8 & 4673.0 & 16 & 6646.4 \\
\hline Liaoning & 128.8 & 288.0 & 41.9 & 124.4 & 4351.7 & 17 & 5778.4 \\
\hline Ningxia & 33.2 & 75.1 & 14.0 & 41.3 & 694.7 & 3 & 1110.1 \\
\hline Qinghai & 21.5 & 58.1 & 8.4 & 41.1 & 607.8 & 2 & 883.4 \\
\hline Shaanxi & 159.7 & 319.0 & 64.4 & 200.9 & 3876.2 & 18 & 6042.7 \\
\hline Shandong & 282.5 & 545.6 & 125.3 & 295.1 & 10070.2 & 29 & 12284.8 \\
\hline Shanxi & 124.4 & 235.6 & 62.0 & 124.1 & 3729.2 & 12 & 4935.6 \\
\hline Sichuan & 297.0 & 759.6 & 148.3 & 302.4 & 8372.0 & 26 & 11184.3 \\
\hline Tibet & 9.7 & 16.4 & 1.5 & 8.6 & 351.0 & 1 & 406.4 \\
\hline Xinjiang & 40.2 & 139.0 & 6.4 & 87.0 & 2527.0 & 8 & 2823.5 \\
\hline Yunnan & 130.2 & 353.2 & 64.0 & 186.6 & 4858.3 & 14 & 5964.1 \\
\hline Zhejiang & 544.6 & 336.5 & 121.0 & 243.9 & 5850.0 & 28 & 11304.7 \\
\hline Beijing & 397.6 & 755.9 & 49.9 & 295.7 & 2153.6 & 20 & 6862.0 \\
\hline Chongqing & 195.1 & 1145.8 & 82.8 & 531.8 & 3124.3 & 15 & 6025.2 \\
\hline Shanghai & 348.2 & 926.1 & 88.0 & 486.9 & 2428.1 & 22 & 7385.7 \\
\hline Tianjin & 151.2 & 568.4 & 41.2 & 272.1 & 1562.0 & 9 & 3544.9 \\
\hline
\end{tabular}

Data source: Baidu Migration website and National Bureau of Statistics of China website

Notes:

$x^{\prime}{ }_{1}$ : The total emigration index of travelers leaving for other provinces from January to February in 2020. 
$x^{\prime}{ }_{2}$ : The total inter-city emigration index within the same province from January to February in 2020.

$x^{\prime}{ }_{3}$ : The total emigration index of travelers leaving foe other provinces in March, 2020.

$x^{\prime}{ }_{4}$ : The total inter-city emigration index within the same province in March,2020.

$x^{\prime} 5$ : The population size of each province in 2020.

$x^{\prime}{ }_{6}$ : The inverse ranking of the provincial GDP in the Q1 of 2019

$Y^{\prime}$ : The predicted nominal GDP of each province in the Q1 of 2019.

We predict that the nominal GDP of China in the Q1 of 2020 is RMB 20,785.7 billion, which is less by 3.59\% when compared to the same period of last year (RMB 21,560 billion). This result is confirmed roughly by the official report released on April 17, 2020 (RMB 20,650 billion).

According to the GDP data of each province in the Q1 of 2020 published by the National Bureau of Statistics, we conducted a correlation analysis over the predicted results, and the analytical results are shown in Figure 3.

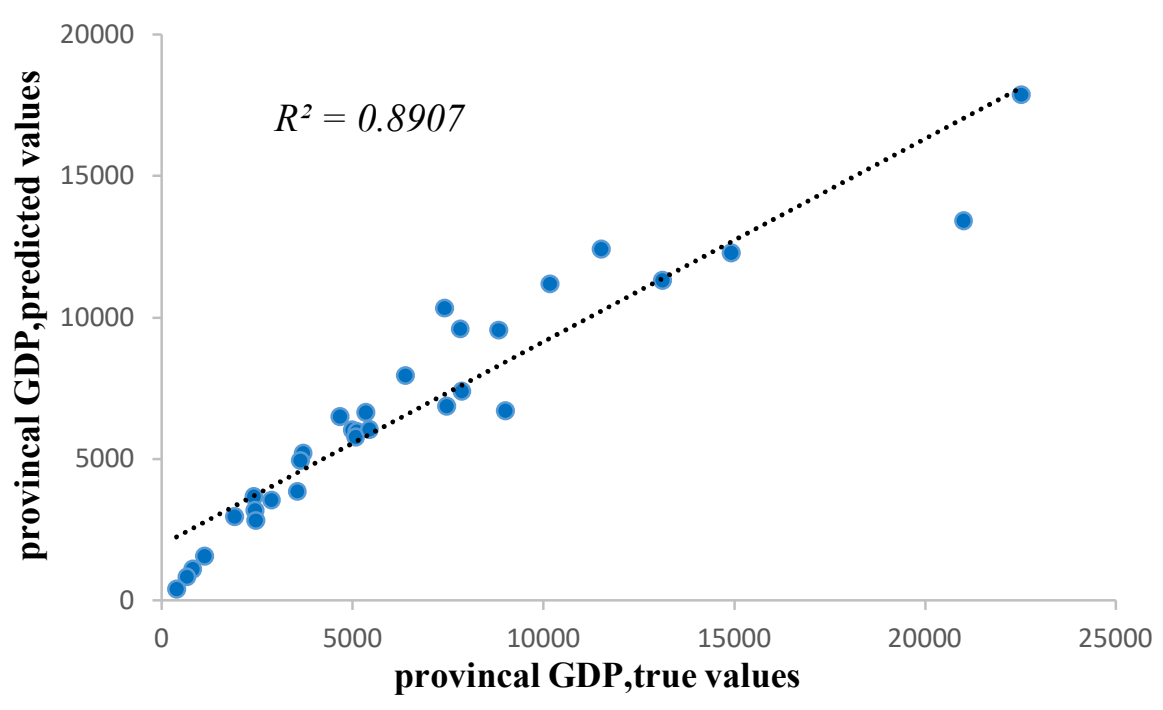

Figure 3. The true and the predicted GDPs of 31 provinces of China's mainland in the Q1 of 2020

\section{Results}

We used the stepwise linear regression method to select relevant parameters from the Baidu Migration Data and established a regression equation to predict the nominal GDP of China's mainland in the Q1 of 2020 is RMB 20,785.7 billion, which is less by $3.59 \%$ than that in 2019 . Validity of this predicted value is strongly supported by the official report released on April 17, 2020 (RMB 20,650 billion). The Population mobility data provides an important reference method and a view for evaluating the impact of the epidemic on other economies and the global as a whole, and also provides a new indicator for the real-time economic prediction when the epidemic ends.

Due to the international flights data is unobtainable, the international population mobility is not considered in our research, which may be one reason for the higher predicted value of this paper. It is an interesting topic to predict the GDP by using the real-time population mobility data and the leading PMI indicator. Since the Baidu Migration has stopped disclosing its migration data for theQ2 of 2020 from May 8th, we do not forecast and assess the GDP of China's mainland in the Q2 of 2020.

\section{Discussion}

Although the population mobility has increased significantly since March and the PMI has rebounded sharply, China's economy in 2020 is still not optimistic because it will continue to suffer from the global epidemic, and the expected target of the annual growth rate is most likely less than $6 \%$. According to the National Bureau of Statistics of China, China's economy grew by 3.2\% year-on-year in the Q2, which is still lower than expected. Some suggestions are provided here. 1) Continue to actively enlarge the domestic demand. For example, fully 
playing the advantages of China's large-scale market, actively enlarging the residential consumption, reasonably increasing the public consumption, starting the consumption in physical stores, continuing to maintain the online consumption enthusiasm, and releasing the consumption demand being suppressed for the epidemic. 2) Reasonably enlarge the effective investment scale. For example, accelerating the construction of $5 \mathrm{G}$ network, data center and other new infrastructure, focusing on the layout of digital economy, life and health, new materials, and other emerging strategic industries and future industries. 3) Precision foreign trade. For example, guiding foreign trade enterprises to adjust their production capacity and structure so as to meet the special global consumption demand during the pandemic, and be a better "world factory" to fight against the pandemic. 4) Continue to carry out the proactive fiscal policy and the moderately easy monetary policy, further reduce taxes, fees and interest rates.

Supplementary Materials: Code and data are available on the following GitHub repository: https://github.com/XiaoYii/Migration-economic-data.

Author Contributions: Data curation, Yi Xiao; Formal analysis, Yi Xiao and Yuan Chen; Resources, Yi Xiao; Software, Yuan Chen; Writing - original draft, Yi Xiao and Zheming Yuan; Writing - review \& editing, Jian Peng.

Funding: This research was funded by the Scientific Research Foundation of Education Office of Hunan Province, China (17A096).

Acknowledgements: We thank Baidu for providing population mobility data.

Conflicts of Interest: The authors declare no conflict of interest. The funders had no role in study design, data collection and analysis, the decision to publish, or in preparation of the manuscript.

\section{References}

1. Huang, C., Wang, Y., Li, X., Ren, L., Zhao, J., Hu, Y., Zhang, L., Fan, G., Xu, J., Gu, X., Cheng, Z., Yu, T., Xia, J., Wei, Y., Wu, W., Xie, X., Yin, W., Li, H., Liu, M., Xiao, Y., Gao, H., Guo, L., Xie, J., Wang, G., Jiang, R., Gao, Z., Jin, Q., Wang, J., Cao, B.,(2020). Clinical features of patients infected with 2019 Novel Coronavirus in Wuhan, China. LANCET, 395(10223), 497-506.

2. Tian. H., Liu, Y., Li, Y., Wu, C., Chen, B., Kraemer, M., Li, B., Cai, J., Xu, B., Yang, Q., Wang, B., Yang, P., Cui, Y., Song, Y., Zheng, P., Wang, Q., Bjornstad, O., Yang, R., Grenfell, B., Pybus, O., Dye, C., (2020). An investigation of transmission control measures during the first 50 days of the COVID-19 epidemic in China. SCIENCE, 368(6491), 638-642.

3. Kraemer, M., Yang, C., Gutierrez, B., Wu, C., Klein, B., Pigott, D., Open COVID-19 Data Working Group; Plessis, L., Faria, N., Li, R., Hanage, W., Brownstein, J., Layan, M., Vespignani, A., Tian, H., Dye, C., Pybus, O., Scarpino, S.,(2020). The effect of human Mobility and Control Measures on the COVID-19 Epidemic in China. SCIENCE, 368(6490), 493-497.

4. Yuan, Z., Xiao, Y., Dai, Z., Huang, J., Chen, Y., (2020). Modelling the effects of Wuhan's lockdown during COVID-19, China. B WORLD HEALTH ORGAN, 98(7), 484-494.

5. Goldschlag, N., Lane, J., Weinberg, B., Zolas, N., (2019). Proximity and Economic Activity: An Analysis of Vendor-University Transactions. J REGIONAL SCI, 59, 163-182.

6. Bunten, D., Weiler, S., Thompson, E., Zahran, S., (2015). Entrepreneurship, Information, and Growth. J REGIONAL SCI, 55, 560584.

7. Yin, P., Lin, Z., Prideaux, B., (2019). The impact of high-speed railway on tourism spatial structures between two adjoining metropolitan cities in China: Beijing and Tianjin. J TRANSP GEOGR, 80: 102495.

8. Afshar, T., Arabian, G., Zomorrodian, R., (2007). Stock return, consumer confidence, purchasing managers index and economic fluctuations. JBER, 5(8),97-106.

9. Aprigliano, V. (2011). The relationship between the PMI and the Italian index of industrial production and the impact of the latest economic crisis. Bank of Italy Temi di Discussione (Working Paper) No, 820.

10. Baidu Migration. Data on Population mobility in China. (2020).http://qianxi.baidu.com [cited 2020 May 8]

11. Stevenson, S. (2007). A comparison of the forecasting ability of ARIMA models. JPIF, 25(3), 223-240.

12. Khashei, M., Bijari, M., Hejazi, S. (2012). Combining seasonal ARIMA models with computational intelligence techniques for time series forecasting. APPL SOFT COMPUT, 16(6), 1091-1105.

13. Lindsey, M., Pavur, R. (2005). As the PMI turns: a tool for supply chain managers. JSCM, 41(1), 30-39.

14. Eren, O. (2014). Forecasting the Relative Direction of economic growth by Using the Purchasing Managers' Index. IKTISAT ISLET FINANS, 29(344),55-72.

15. Lahiri, K., Monokroussos, G. (2013). Nowcasting US GDP: The role of ISM business surveys. INT J FORECASTING, 29, 644-658.

16. Rolando, F. (2018). Improving the usefulness of the Purchasing Managers' Index. B ECON, 53,195-201.

17. Tektüfekçi F., Kutay N. (2016). The relationship between EPI and GDP growth: an examination on developed and emerging countries. JMAA, 12(5), 268-276.

18. National Bureau of Statistics. The official release of Chinese statistics. (2020) .http://www.stats.gov.cn/ [cited 2020 March22] 